Pathophysiology

of Haemostasis and Thrombosis
Pathophysiol Haemost Thromb 2007-08;36:259-265

DOI: $\underline{10.1159 / 000252822}$
Received: March 2, 2009

Accepted after revision: April 13, 2009

\title{
Prothrombin Complex Concentrates for Urgent Anticoagulation Reversal in Patients with Intracranial Haemorrhage
}

\author{
D. Imbertia ${ }^{a}$ G. Barillari ${ }^{b} \quad$ C. Biasiolic ${ }^{c}$ M. Bianchi ${ }^{d} \quad$ L. Contino $^{e} \quad$ R. Duce $^{f}$ \\ M. D'Incàg $\quad$ L. Mameli ${ }^{\text {h }} \quad$ L. Pinna ${ }^{i} \quad$ W. Ageno ${ }^{j}$
}

${ }^{a}$ Ospedale Civile, Piacenza, ${ }^{b}$ Ospedale S. Maria Misericordia, Udine, ${ }^{\circ}$ Ospedale Civile, Cesena, ${ }^{d}$ Ospedale Valduce, Como, ${ }^{e}$ Ospedale Civile, Alessandria, ${ }^{f}$ Ospedale Galliera, Genova, ${ }^{9}$ Ospedale S. Maria Nuova, Reggio Emilia,

hospedale Civile, Sassari, 'Ospedale Brotzu, Cagliari, and 'Università dell'Insubria, Varese, Italy

\section{Key Words}

Intracranial haemorrhage $\cdot$ Oral anticoagulants •

Prothrombin complex concentrates

\begin{abstract}
Background: Intracranial haemorrhage $(\mathrm{ICH})$ is a serious and potentially fatal complication of oral anticoagulant therapy (OAT). Prothrombin complex concentrates (PCCs) produce a rapid and effective reversal of OAT effects, but little evidence exists on their efficacy and safety in the management of $\mathrm{ICH}$ in patients on OAT. Aim: To evaluate the efficacy and safety of PCCs for the rapid reversal of OAT in patients with $\mathrm{ICH}$. Methods: Patients suffering from acute $\mathrm{ICH}$ while receiving OAT were eligible for this prospective cohort study if their international normalized ratio (INR) was $\geq 2.0$. Stratified 35 $50 \mathrm{IU} \mathrm{kg}^{-1}$ PCC doses were infused based on initial INR. $\boldsymbol{R e}$ sults: A total of 92 patients (50 males; mean age 74 years, range 34-92 years) were included. The median INR at presentation was 3.3 (range 2-9). At $30 \mathrm{~min}$ after PCC administration the median INR was 1.4 (range 0.9-3.1), declining to $\leq 1.5$ in $75 \%$ of patients. The benefit of PCC was maintained for a long time, since in $98 \%$ of all post-infusion time points through $96 \mathrm{~h}$ the median INR remained $\leq 1.5$ (median 1.19; range 0.9-2.3). During hospitalization neither thrombotic
\end{abstract}

complications nor significant adverse events were observed and 11 patients died (11.9\%). None of the deaths was judged to be related to PCC administration. Conclusions: PCC administration is an effective, rapid and safe treatment for the urgent reversal of OAT in patients with $\mathrm{ICH}$. Broader use of PCC in this clinical setting appears to be appropriate.

Copyright ๑ 2009 S. Karger AG, Basel

\section{Introduction}

Oral anticoagulant therapy (OAT) is an effective and commonly used treatment for long-term primary and secondary prophylaxis of arterial (including atrial fibrillation, mechanical heart valves) and venous thrombosis (such as deep vein thrombosis and pulmonary embolism) [1]. Despite meticulous surveillance of the treatment by regular international normalized ratio (INR) monitoring, bleeding events are frequent, and intracranial haemorrage $(\mathrm{ICH})$ remains the most serious and potentially fatal complication of OAT [2-6]. ICHs account for about $20-30 \%$ of the major bleeding complications reported in large-scale epidemiological studies involving patients receiving OAT, in which the annual incidence of fatal or life-threatening bleeding complications was reported be-

\section{KARGER}

Fax +41613061234

E-Mail karger@karger.ch

www.karger.com
(C) 2009 S. Karger AG, Basel

$1424-8832 / 08 / 0365-0259 \$ 24.50 / 0$

Accessible online at:

www.karger.com/pht
Davide Imberti

Thrombosis Center, Emergency Department

Piacenza Hospital, Via Taverna 49

IT-29100 Piacenza (Italy)

Tel. +39 0523303 313, Fax +390523 303 315, E-Mail d.imberti@ausl.pc.it 
tween 1 and 3\% [2, 7]. Moreover, in patients with OATassociated $\mathrm{ICH}$, mortality is very high, ranging from 50 to $60 \%[8,9]$.

Timely and complete reversal of OAT is required in patients suffering from $\mathrm{ICH}$ in whom immediate replacement of functional coagulation factors is indicated. Fresh frozen plasma (FFP) is a possible option, even if the time to prepare and infuse it could be associated with a clinically important delay of effective administration. Moreover, the effect may be inadequate especially in patients with exceedingly high INR values [10], and volume overload is a frequent complication observed following rapid transfusion of large volumes of FFP [10, 11].

Prothrombin complex concentrate (PCC) is human plasma-derived and contains vitamin K-dependent coagulation factors II, IX, X and VII (the latter not in preparations licensed in Italy) in a concentrated form and in a well-standardized amount. PCCs produce a rapid and adequate action and substantially shorten the time needed to reverse OAT effects [12-15]. Moreover, these products are virally inactivated and can be administered very rapidly without the need for matching the blood group or thawing the product [16]. In addition, a number of studies enrolling small numbers of patients have suggested that PCCs are able to correct more quickly and completely warfarin-related coagulopathy than FFP $[10,11,17-19]$ and to reduce the risk of haematoma growth [20]. For these considerations, several clinical guidelines recommend that PPC infusion should be administered instead of FFP for urgent reversal of anticoagulation in patients with life-threatening bleeding [1,21-23]. However, there are currently no clinical studies that have adequately assessed the efficacy and safety of PCCs in a sufficiently large group of patients with the most threatening complication of OAT, that is, ICH.

The aim of this prospective, multicenter cohort study was therefore to evaluate the efficacy and safety of PCC infusion for rapid reversal of OAT and bleeding control in patients with acute $\mathrm{ICH}$.

\section{Patients and Methods}

\section{Study Population}

Patients admitted to 10 Italian centers with objectively diagnosed (computed tomography or nuclear magnetic resonance scan) acute symptomatic ICH during OAT and with an INR $\geq 2.0$ were eligible for inclusion. Other inclusion criteria were age $\geq 18$ years and the obtainment of written informed consent. If a candidate was unable to sign informed consent, consent could be obtained from a legal representative or a family member of the pa- tient. Exclusion criteria were concomitant acute ischemic cardiovascular disorder, disseminated intravascular coagulation, sepsis, pregnancy, breast feeding and mental retardation. Patients were recruited $24 \mathrm{~h}$ a day and 7 days a week.

\section{Treatment}

All included patients received $35-50 \mathrm{IU} \mathrm{kg}^{-1}$ body weight of Protromplex (Baxter, Milan, Italy). Protromplex is a biochemically well-balanced PCC derived from plasma prepared using pasteurization and nanofiltration and contains the following coagulation factors: factor II $(35.5 \mathrm{IU} / \mathrm{ml})$, factor IX $(31.8 \mathrm{IU} / \mathrm{ml})$ and factor X $(28.6 \mathrm{IU} / \mathrm{ml})$. Protromplex is manufactured from plasma which is subjected to a robust safety program including plasma/ donor selection, extended virus screening, non-returning donor rejection, $>3$ months inventory hold, look-back and IQ-PCR testing for all plasma pools (HIV, HBV, HCV). Protromplex undergoes a virus inactivation process through a 2 -step steam treatment $\left(10 \mathrm{~h}\right.$ at $60^{\circ} \mathrm{C}$ plus $1 \mathrm{~h}$ at $\left.80^{\circ} \mathrm{C}\right)$ and several virus-partitioning steps [24].

PCCs were administered within $6 \mathrm{~h}$ from $\mathrm{ICH}$ diagnosis at different doses depending on baseline INR levels: $35-39 \mathrm{IU} \mathrm{kg}^{-1}, 40$ $45 \mathrm{IU} \mathrm{kg}^{-1}$ or $46-50 \mathrm{IU} \mathrm{kg}^{-1}$ body weight doses were infused to patients with baseline INRs of 2.0-3.9, 4.0-6.0 or $>6.0$, respectively. Prior to PCC infusion, all patients were also treated with intravenous infusion of $10 \mathrm{mg}$ of vitamin K. Concomitant therapy with whole blood, plasma or plasma fraction was not allowed within the first $30 \mathrm{~min}$ after PCC infusion, unless urgently required as judged by the attending clinician. Conversely, an additional infusion of PCCs was allowed at intervals of $6 \mathrm{~h}$ after the administration of the first dose, depending on the INR level reached.

\section{Study Outcomes}

The primary end-point of the study was the rate of INR values of $\leq 1.5$ after $30 \mathrm{~min}$ from the infusion of PCCs; prespecified secondary end-points included the rate of INR levels $\leq 1.5$ at 6,24 , 48,72 and $96 \mathrm{~h}$ after infusion. Clinical end-points included mortality, ICH recurrences, thromboembolic complications, viral infections, adverse events, need for neurosurgical drainage of the haematoma and time to resumption of OAT. The occurrence of clinical end-points was monitored throughout hospital stay and within 90 days of follow-up. The adjudication of the end-points was done locally.

\section{Laboratory and Clinical Assessment}

Blood samples were collected for determination of INR prior to infusion and at intervals of $0.5,6,24,48,72$ and $96 \mathrm{~h}$ afterward. Prothrombin time, activated partial thromboplastin time, fibrinogen, haemoglobin, platelet count and D-dimer were determined at baseline and after 0.5, 6 and $24 \mathrm{~h}$. The INR and the haematology parameters were measured at the local laboratories of the study centres. At enrolment, all patients underwent a complete clinical assessment that included medical history, physical examination and determination of vital signs. The occurrence of any adverse events (including death, thromboembolic complications, $\mathrm{ICH}$ recurrences and allergic reactions) was monitored after 7, 30 and 90 days, as well as the need for urgent neurosurgery. Viral exposure was evaluated at baseline and 7, 30 and 90 days after infusion of PCCs. In all patients, the eventual resumption of OAT during follow-up was registered. 
Sample Size and Statistical Analysis

All statistical analyses were performed with the use of SPSS software version 11.0. Continuous variables such as INR values were analysed using ANOVA test for repeated measurements with the Dunnett multicomparison test. The $95 \%$ confidence intervals (CI) were also calculated for categorical variables expressed as percentages. All statistical tests were two-sided and $\mathrm{p}<0.05$ was considered statistically significant. For sample size calculation, the following considerations were performed. The primary efficacy end-point of this prospective cohort study was considered the percentage of patients achieving an INR value $<1.5$ after at least $30 \mathrm{~min}$ following the PCC infusion. We hypothesized that at least $90 \%$ of OAT patients treated with PCC could achieve an INR value $<1.5$ six hours after the infusion of PCC. Therefore, with a sample size population of at least 90 patients, a percentage of $90 \%$ of 'successes' has a $95 \%$ CI of $83-96 \%$. Thus, with a success rate of $90 \%$ and a sample size of at least 90 subjects we could be confident that PCC infusion could achieve a percentage of successes above $80 \%$.

The study was performed in accordance with the International Conference on Harmonization Good Clinical Practice guidelines and the 1996 Declaration of Helsinki. Moreover, the study protocol was approved by the local ethic committees of the participating centres.

\section{Results}

Between October 2005 and December 2007, 92 patients were enrolled; 52 patients were admitted in emergency departments, 23 in neurosurgical departments, 12 in internal medicine departments and 5 in stroke units. One patient was excluded from the analysis of the results because he was treated before the INR was available and his pre-treatment baseline INR turned out to be 1.7. Baseline characteristics of the patients are reported in table 1 and indications for OAT use are summarized in table 2.

ICH was spontaneous in 52 patients (56\%) and posttraumatic in the remaining 40 patients (44\%). 74 patients $(80 \%)$ presented with intracerebral haemorrhage, 12 (13\%) with subdural haemorrhage and $6(7 \%)$ with subarachnoidal haemorrhage. 42 patients (45\%) underwent urgent craniotomy for evacuation of the haemorrhage.

According to the baseline INR levels (table 1), a single PCC dose of 35-39, 40-45 and 46-50 IU kg-1 body weight was infused in 73,13 and 6 patients, respectively [24,25]. The mean rate of PCC administration was 2,386 IU per patient (SD $728 \mathrm{IU}$, range 500-4,000 IU), over a mean infusion time of $30 \mathrm{~min}$ (SD $0.7 \mathrm{~min}$, range 15-60 min). All patients received concomitant vitamin K (10 mg intravenously); 1 patient also received FFP as part of his anticoagulation reversal.

The median INR at presentation was 3.3 (range 2-9). At 30 min after PCC administration the median INR was

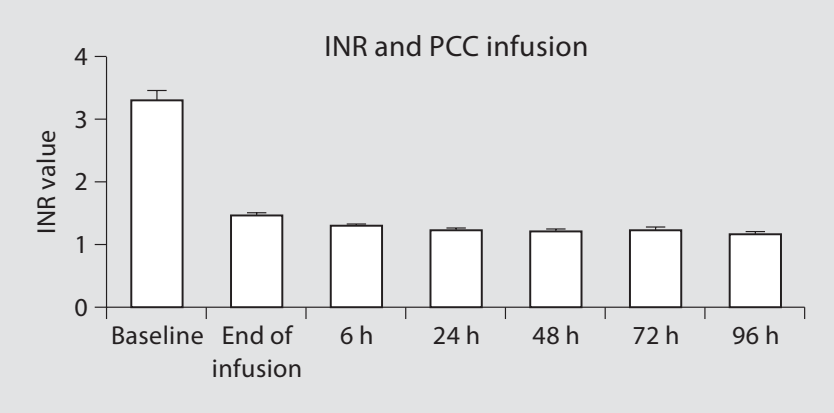

Fig. 1. INR values before and after PCC infusion.

Table 1. Demographic and clinical baseline patient data

\begin{tabular}{lc}
\hline & Descriptive statistics \\
\hline Mean age, years & $74(34-92)$ \\
Sex, males/females & $50 / 42$ \\
Body weight, kg & $70.3 \pm 18.5$ \\
INR & $73(79 \%)$ \\
$\quad 2-3.9$ & $13(14 \%)$ \\
$\quad 4-6$ & $6(7 \%)$ \\
Oral anticoagulant & $72(78 \%)$ \\
$\quad$ Warfarin & $20(22 \%)$ \\
$\quad$ Acenocumarol &
\end{tabular}

Table 2. Indications for OAT use

\begin{tabular}{lc}
\hline & Patients \\
\hline Atrial fibrillation & $50(54 \%)$ \\
Mechanical heart valves & $22(24 \%)$ \\
Venous thromboembolism & $18(16 \%)$ \\
Severe cardiomyopathy & $2(6 \%)$ \\
\hline
\end{tabular}

significantly reduced to 1.4 (range $0.9-3.1 ; \mathrm{p}<0.0001$ ), declining to $\leq 1.5$ in $75 \%$ of patients. Only 5 patients (5.4\%) with an INR exceeding 2.0 after first administration of PCC received a second infusion of the concentrates.

The benefit of PCC was maintained for a long time, since in $98 \%$ of all post-infusion time points through $96 \mathrm{~h}$ the median INR remained $\leq 1.5$ (median 1.19 , range $0.9-$ 2.3; fig. 1). In detail, the median INR values at pre-treatment, $30 \mathrm{~min}, 6,24,48,72$ and $96 \mathrm{~h}$ after treatment were $3.3,1.4,1.2,1.2,1.2$ and 1.1 , respectively. 
During hospitalization only one patient suffered from non-fatal ICH recurrence, while neither thrombotic complications nor significant adverse events were observed. No case of excessive perioperative bleeding in patients undergoing surgery occurred and in none of them a reintervention was necessary.

After discharge, 5 patients $(5.4 \%, 95 \%$ CI $0.8-10 \%)$ suffered from thromboembolic complications. One 56year-old man died because of the occurrence of an ischaemic stroke 37 days after PCC infusion; he had restarted anticoagulant treatment 5 days after ICH. The patient was at increased risk of thrombosis because of the concomitant presence of a prosthetic mechanical mitral valve and atrial fibrillation. One 79-year-old female was hospitalized for an acute myocardial infarction 47 days after PCC infusion, while taking antiplatelet drugs; her history included arterial embolism and severe cardiomyoapthy. Three patients suddenly developed symptoms suggestive for acute deep vein thrombosis of the lower limbs, at 70, 85 and 87 days after PCC therapy; their history included previous deep vein thrombosis (2 patients) and pulmonary embolism (1 patient). In all of them, OAT had not been resumed and a prophylactic dose of low-molecular-weight heparin had been started. Color duplex sonography revealed acute thrombosis of the right popliteal vein ( 2 patients) and of the left femoro-popliteal vein (1 patient). Overall, 18 patients (19\%, 95\% CI 11-27\%) died, 11 patients during hospitalization and 7 after discharge. None of the deaths was judged to be related to PCC administration. Of note, during the study period, OAT therapy was not resumed in 15 patients, since it was judged to be either unnecessary or associated with an excessive risk of recurrence of bleeding.

In no patients was there evidence of viral transmission or other adverse events at the end of follow-up. No patient had a diagnosis of fluid overload associated with the reversal process.

\section{Discussion}

Bleeding is the most frequent complication of OAT [1], but only few studies have focused on treatment options available for the acute reversal of anticoagulation in case of ICH. To our knowledge, this is the largest study that has specifically evaluated the efficacy and safety of PCCs for the management of ICH in OAT patients. The results of our study suggest that PCC infusion produces an effective and long-lasting reversal of OAT by rapidly nor- malizing INR levels in nearly all cases. In our cohort of patients, we neither observed thrombotic complications nor significant adverse events in the immediate postinfusion period; no case of excessive perioperative bleeding in patients undergoing surgery occurred. The longterm safety of our management strategy was also supported by the low rate of adverse events at 3-month follow-up.

Our experience compares favourably with previously published series describing the use of PCCs for urgent reversal of warfarin in patients with major bleedings, including ICH [25-30]. Lankiewicz et al. [29] retrospectively investigated the feasibility, efficacy and safety of administering PCCs to urgently reverse the anticoagulant effect of warfarin in 58 patients enrolled in a single center; 36 of them (62\%) presented with ICH. PCC doses were determined according to baseline INR levels, ranging between 25 and $50 \mathrm{IU} \mathrm{kg}^{-1}$. PCC administration was very effective, since immediately after infusion $76 \%$ of the patients had INR levels $<1.5$ and $96.5 \%$ had INR levels <2.0. Pabinger et al. [30] prospectively evaluated whether balanced PCCs allow INR normalization (defined as INR levels of $\leq 1.3$ ) in 43 anticoagulated patients requiring either an emergency surgical or urgent invasive diagnostic intervention or suffering from an acute major bleeding. The study demonstrated that PCC treatment was an effective rapid hemorrhage control resource in the emergency anticoagulant reversal setting, since $30 \mathrm{~min}$ after treatment infusion the INR levels declined to $\leq 1.3$ in $93 \%$ of the treated patients. Yasaka et al. [17] enrolled 42 anticoagulated patients admitted to an emergency department for major haemorrhagic complications, 35 of whom involved the central nervous system; this trial showed the efficacy of PCCs to rapidly normalize the INR values in almost all cases. Finally, Viguè et al. [31] investigated efficacy and safety of PCC for ultra-rapid INR normalization in 18 anticoagulated patients with ICH requiring urgent surgery. This study demonstrated that a bolus infusion of PCC ( $1 \mathrm{~min})$ was able to completely reverse anticoagulation within $3 \mathrm{~min}$ in all patients. Other studies have also demonstrated the utility of PCC infusion for rapid and complete reversal of anticoagulation $[10,13,14]$.

In our study, the overall mortality during hospitalization and within 90 days of follow-up was 19\%; this figure is much lower than that shown in historical series in untreated patients, in whom the reported mortality rate was about $50-60 \%[8,9]$. Of interest, the mortality rate observed in our trial was similar to that shown in a small study of anticoagulated patients treated with PCC for an 
acute ICH, in which $22 \%$ of the cases died within 6 months of follow-up [31].

In our study, we have used a 3-factor PCC, which contains only factors II, IX and X in approximately equal quantities, with no detectable factor VII activity; currently, in Italy only 3-factor PCCs are available. Moreover, administration of PCCs with significant factor VII content does not seem to be essential, or any more effective, than PCCs with low (or absent) factor VII activity to reverse warfarin-induced bleeding complications [32]; however, until now no head-to-head PCC comparative studies have been conducted to explore this issue.

Even if PCCs are actually considered the optimal therapeutic option for the acute reversal of OAT in patients with ICH [21,22], there is a paucity of studies comparing their efficacy with other available haemostatic interventions, such as FFP and recombinant activated factor VII (rVIIa). In the studies that compared PCCs with FFP, PCCs showed a substantially more rapid and stable effect than FFP $[10,11,18,20]$. rVIIa has shown promising results in this setting [33-35], but no randomized clinical trials have yet compared its efficacy and safety against PCCs or FFP. In a sustained anticoagulation animal model designed to simulate standard long-term oral coumarin therapy in patients, PCC was shown to be more effective than rVIIa in restoring haemostatic function [36]. Moreover, in an experimental study using in vivo rat and in vitro human models of anticoagulation, both PCC and rVIIa were associated with a reversal of prothrombin time, but only PCC restored overall thrombin generation [37]. The very short half-life of rVIIa can be a serious drawback for the treatment of bleeding in anticoagulated patients, with the risk of exposing the patients to a potentially dangerous time window of persistent anticoagulant effect [16].

The results of our trial add important information on the use of PCCs for the urgent reversal of warfarin in patients with ICH. Firstly, our population was quite homogenous when compared to those enrolled in other similar trials. In fact, we have included only patients requiring reversal of warfarin because of an acute $\mathrm{ICH}$, while all other published trials have recruited anticoagulated patients requiring urgent reversal for surgical or invasive diagnostic interventions [30] or INR normalization because of acute bleeding in different sites $[29,30,36]$. Second, in most previous studies the INR values were followed for a short time, usually not exceeding $24 \mathrm{~h}$ after infusion [29, 36]. In our study we evaluated the long-term time course of change in INR, showing that the benefit of

PCCs for Urgent Anticoagulation Reversal in Patients with ICH
PCCs was maintained for a long time; in fact, in $98 \%$ of all post-infusion time points through $96 \mathrm{~h}$, median INR remained $\leq 1.5$. Finally, we have data about the rate of reintroduction of anticoagulant therapy; in our study at the end of the follow-up (90 days after ICH), 59 patients had restarted anticoagulant treatment without recurrent bleeding.

Other clinical observations also support the efficacy of this approach. In fact, in the group undergoing surgery we observed neither perioperative excessive bleeding complications nor the need for re-intervention. Moreover, in our series the overall mortality was $19.6 \%$, a rate which is lower than that reported in other previous studies $[3,29]$.

A potential complication of PCC administration is the occurrence of venous and arterial thromboembolism [12, $13,29,30]$. In our series, no case of thrombosis occurred during the initial hospitalization, while we observed five late thromboembolic events during the follow-up period. Given the broad time frame between PCC administration and the occurrence of thrombotic events, it is unlikely that all observed events can be related to the use of PCCs. Finally, no case of viral transmission was registered at the end of the follow-up.

This study has some limitations. First, we did not include a control group. The use of an untreated control group was obviously not ethical; moreover, since several European clinical guidelines recommend PPC infusion as the treatment of choice for the urgent reversal of anticoagulation in patients with life-threatening bleeding $[21,22]$, a comparison with other haemostatic agents (such as FFP or rVIIa) was unfeasible. Second, because of the relatively small sample size, the patients included in this study may not be representative of the overall population and, therefore, definitive conclusions cannot be drawn from these data. However, this is, to our knowledge, the largest study ever published on emergency anticoagulation reversal in patients with $\mathrm{ICH}$; moreover, the practical difficulties associated with obtaining suitable patients in this clinical setting make our results, albeit limited, of interest. Finally, the clinical significance of our findings could be considered questionable, since the primary end-point of the study was based on a surrogate marker of efficacy, that is reduction of INR levels [38]. However, the association between INR levels and the risk of bleeding complications is well established.

In conclusion, PCC administration is an effective, rapid and safe treatment for the urgent reversal of OAT in patients with ICH; unfortunately, this important resource 
still seems to be underused in daily clinical practice for the treatment of this potentially life-threatening complication $[4,5,37]$. A broader use of PCCs in this clinical setting should be encouraged.

\section{Acknowledgments}

The investigators wish to thank Baxter (Milan, Italy) for supporting this study with an unrestricted educational grant. The sponsor had no role in the design and conduct of the study, management, analysis and interpretation of the data, nor in the preparation, review or approval of the manuscript.

\section{References}

1 Ansell J, Hirsh J, Hylek E, Jacobson A, Crowther M, Palareti G: Pharmacology and management of the vitamin $\mathrm{K}$ antagonists: American College of Chest Physicians Evidence-Based Clinical Practice Guidelines (8th Edition). Chest 2008;133:160S-198S.

2 Palareti G, Leali N, Coccheri S, Poggi M, Manotti C, D’Angelo A, Pengo V, Erba N, Moia M, Ciavarella N, Devoto G, Berrettini M, Musolesi S: Bleeding complications of oral anticoagulant treatment: an inception-cohort, prospective collaborative trial (ISCOAT). Lancet 1996;348:423-428.

- 3 Davis SM, Broderick J, Hennerici M, Brun NC, Diringer MN, Mayer SA, Begtrup K, Steiner T, Recombinant Activated Factor VII Intracerebral Hemorrhage Trial Investigators: Hematoma growth is a determinant of mortality and poor outcome after intracerebral hemorrhage. Neurology 2006;66:11751181.

4 Nicolini A, Ghirarduzzi A, Iorio A, Silingardi M, Malferrari G, Baldi G: Intracranial bleeding: epidemiology and relationships with antithrombotic treatment in 241 cerebral hemorrhages in Reggio Emilia. Haematologica 2002;87:948-956.

5 Baldi G, Altomonte F, Altomonte M, Ghirarduzzi A, Brusasco C, Parodi RC, Ricciardi A, Remollino V, Spisni V, Saporito A, Caiazza A, Musso G, Cervellin G, Lamberti S, Buzzalino M, De Giorgi F, Del Prato C, Golinelli MP, Gai V, Monsù R, Gioffrè M, Giovanardi D, Cattaneo S, Frumento F, Caporrella A, Re G, De Iaco F, Bologna G, Nocenti F, Lorenzi C, Zoratti R, Sciolla A, Tiscione V, Pastorello M, Vandelli A, Villa A, Zanna M, De Palma A, Iorio A: Intracranial haemorrhage in patients on antithrombotics: clinical presentation and determinants of outcome in a prospective multicentric study in Italian emergency departments. Cerebrovasc Dis 2006;22:286-293.

6 Garcia DA, Regan S, Crowther M, Hylek EM: The risk of hemorrhage among patients with warfarin-associated coagulopathy. J Am Coll Cardiol 2006;47:804-808.

7 Go AS, Hylek EM, Chang Y, Phillips KA, Henault LE, Capra AM, Jensvold NG, Selby JV, Singer DE: Anticoagulation therapy for stroke prevention in atrial fibrillation: how well do randomized trials translate into clinical practice? JAMA 2003;290:2685-2692.
-8 Rosand J, Eckman MH, Knudsen KA, Singer DE, Greenberg SM: The effect of warfarin and intensity of anticoagulation on outcome of intracerebral hemorrhage. Arch Intern Med 2004;164:880-884.

-9 Aguilar MI, Hart RG, Kase CS, Freeman WD, Hoeben BJ, García RC, Ansell JE, Mayer SA, Norrving B, Rosand J, Steiner T, Wijdicks EF, Yamaguchi T, Yasaka M: Treatment of warfarin-associated intracerebral hemorrhage: literature review and expert opinion. Mayo Clin Proc 2007;82:82-92.

10 Makris M, Greaves M, Phillips W, Kitchen S, Rosendaal F, Preston E: Emergency oral anticoagulant reversal: the relative efficacy of infusion of fresh frozen plasma and clotting factor concentrate on correction of the coagulopathy. Thromb Haemost 1997;77:477480.

11 Boulis NM, Bobek MP, Schmaier A, Hoff JT: Use of factor IX complex in warfarin-related intracranial hemorrage. Neurosurgery 1999; 45:1113-1118.

12 Yasaka M, Sakata T, Minematsu K, Naritomi $\mathrm{H}$ : Correction of INR by prothrombin complex concentrate and vitamin $\mathrm{K}$ in patients with warfarin related hemorragic complications. Thromb Res 2002;108:25-30.

13 Riess HB, Meier-Hellmann A, Motsch J, Elias M, Kursten FW, Dempfle CE: Prothrombin complex concentrate (Octaplex) in patients requiring immediate reversal of oral anticoagulation. Thromb Res 2007;121:916.

14 Lorenz R, Kienast J, Otto U, Kiehl M, Schreiter D, Haertel S, Barthels M: Successful emergency reversal of phenprocoumon anticoagulation with prothrombin complex concentrate: a prospective clinical study. Blood Coagul Fibrinolysis 2007; 18:565-570.

15 Leissinger CA, Blatt PM, Hoots WK, Ewenstein B: Role of prothrombin complex concentrates in reversing warfarin anticoagulation: a review of the literature. Am J Hematol 2008;83:137-143.

16 Marietta M, Pedrazzi P, Girardis M, Torelli G: Intracerebral haemorrage: an often neglected medical emergency. Intern Emerg Med 2007;2:38-45.

17 Yasaka M, Sakata T, Naritomi H, Minematsu $\mathrm{K}$ : Optimal dose of prothrombin complex concentrate for acute reversal of oral anticoagulation. Thromb Res 2005;115:455-459.
18 Fredriksson K, Norrving B, Stromblad LG: Emergency reversal of anticoagulation after intracerebral hemorrage. Stroke 1992;23: 972-977.

19 Cartmill M, Dolan G, Byrne JL, Byrne PO: Prothrombin complex concentrate for oral anticoagulant reversal in neurosurgical emergencies. Br J Neurosurg 2000;14:458461.

20 Huttner HB, Schellinger PD, Hartmann M, Köhrmann M, Juettler E, Wikner J, Mueller S, Meyding-Lamade U, Strobl R, Mansmann U, Schwab S, Steiner T: Hematoma growth and outcome in treated neurocritical care patients with intracerebral hemorrhage related to oral anticoagulant therapy: comparison of acute treatment strategies using vitamin $\mathrm{K}$, fresh frozen plasma, and prothrombin complex concentrates. Stroke 2006;37:1465-1470.

21 Guidelines of the FCSA: a guide to oral anticoagulant treatment. Haematologica 2003; 88(suppl 2):1-47.

22 Baglin TP, Keeling DM, Watson HG: Guidelines on oral anticoagulation (warfarin): third edition - 2005 update. Br J Haematol 2006;132:277-285.

- 23 Steiner T, Kaste M, Forsting M, Mendelow D, Kwiecinski H, Szikora I, Juvela S, Marchel A, Chapot R, Cognard C, Unterberg A, Hacke $\mathrm{W}$ : Recommendations for the management of intracranial haemorrhage - part I: spontaneous intracerebral haemorrhage. The European Stroke Initiative Writing Committee and the Writing Committee for the EUSI Executive Committee. Cerebrovasc Dis 2006; 22:294-316.

24 Seitz R, Dodt J: Virus safety of prothrombin complex concentrates and factor IX concentrates. Thromb Res 1998;95:S19-S23.

25 Tiraferri E, Galletti M, Argento A: Emergency use of prothrombin complex concentrates in oral anticoagulant therapy: rapid reversal. Haematologica 2004;89:177.

26 van Aart L, Eijkhout HW, Kamphuis JS, Dam M, Schattenkerk ME, Schouten TJ, Ploeger B, Strengers PF: Individualized dosing regimen for prothrombin complex concentrate more effective than standard treatment in the reversal of oral anticoagulant therapy: an open, prospective randomized controlled trial. Thromb Res 2006;118:313320 . 
27 Evans G, Luddington R, Baglin T: Beriplex $\mathrm{P} / \mathrm{N}$ reverses severe warfarin induced overcoagulation immediately and completely in patients presenting with major bleeding. $\mathrm{Br} \mathrm{J}$ Haematol 2001;115:998-1001.

28 Preston FE, Laidlaw ST, Sampson B, Kitchen S: Rapid reversal of oral anticogulation with warfarin by a prothrombin complex concentrate (Beriplex): efficacy and safety in 42 patients. Br J Haematol 2002;116:619-624.

29 Lankiewicz MW, Hays J, Friedman KD, Tinkoff G, Blatt PM: Urgent reversal of warfarin with prothrombin complex concentrate. J Thromb Haemost 2006;4:967-970.

-30 Pabinger I, Brenner B, Kalina U, Knaub S, Nagy A, Ostermann H; Beriplex P/N Anticoagulation Reversal Study Group: Prothrombin complex concentrate (Beriplex $\mathrm{P} / \mathrm{N}$ ) for emergency anticoagulation reversal: a prospective multinational clinical trial. J Thromb Haemost 2008;6:622-631.
31 Viguè M, Ract C, Tremey B, Engrand N, Leblanc PE, Decaux A, Martin L, Benhamou D: Ultra-rapid management of oral anticoagulant therapy-related surgical intracranial haemorrhage. Intensive Care Med 2007;33: 721-725.

32 Kessler CM: Urgent reversal of warfarin with prothrombin complex concentrate: where are the evidence-based data? J Thromb Haemost 2006;4:963-966.

33 Sorensen B, Johansen P, Nielsen GL, Sorensen J, Ingerslev J: Reversal of the International Normalized Ratio with recombinant activated factor VII in central nervous system bleeding during warfarin thromboprophylaxis: clinical and biochemical aspects. Blood Coagul Fibrinolysis 2003;14:469-477.

34 Freeman WD, Brott TG, Barrett KM, Castillo PR, Deen HG Jr, Czervionke LF, Meschia JF: Recombinant factor VIIa for rapid reversal of warfarin anticoagulation in acute intracranial hemorrhage. Mayo Clin Proc 2004;7:1495-1500.
35 Brody DL, Aiyagari V, Shackeford AM, Diringer MN: Use of recombinant factor VIIa in patients with warfarin-associated intracranial hemorrhage. Neurocrit Care 2005;2: 263-267.

36 Dickneite G: Prothrombin complex concentrate versus recombinant factor VIIa for reversal of coumarin anticoagulation. Thromb Res 2007;119:643-651.

37 Appelboam R, Thomas EO: The headache over warfarin in British neurosurgical intensive care units: a national survey of current practice. Intensive Care Med 2007;33:19461953.

38 Tanaka KA, Szlam F, Dickneite G, Levy JH Effects of prothrombin complex concentrate and recombinant activated factor VII on vitamin $\mathrm{K}$ antagonist induced anticoagulation. Thromb Res 2008;122:117-123. 